\title{
Students' Perceptions of Collaborative Summary Writing
}

\author{
Noura Nasser Muhammad Alawaji \\ Qassim University, Saudi Arabia
}

\begin{abstract}
Writing is one of the four main language skills that are given emphasis in Second Language Learning. Summary writing is often viewed as a difficult and a challenging skill in learning a second language, which may result in negative attitudes forming, both toward summary writing and to writing in general. The main purpose of this study is to investigate students' perceptions and problems related to collaborative summary writing in a university in Saudi Arabia. The study involved five undergraduate EFL Saudi female students as a case study and who were exposed to writing course participated in this study. The students were given different collaborative writing tasks during the semester and completed one summary writing task collaboratively for the purpose of this study. Then their views about the task were recorded via semistructured interview. The findings suggest that most of the participants express positive attitudes toward collaborative writing and consider it beneficial for improving different aspects of writing skills, second language proficiency, and confidence. Several problems occurred during the process of collaboration, and these are also identified and discussed.
\end{abstract}

Index Terms - collaborative summary writing, collaborative writing, L2 writing

\section{INTRODUCTION}

Writing is considered to be one of the most important academic skills, especially in settings like schools and universities. Among the different genres of writing, summary writing is found to be challenging and difficult to master, hence, collaborative writing has been suggested as a potential solution (Lin \& Maarof, 2013). Collaborative writing is defined as the joint production of a text by two or more writers (Storch, 2011). In recent years, there has been a significant growth of research on collaborative writing in the L2 classroom (see, for example, Shehadeh, 2011; Storch, 2005; Lin \& Maarof, 2013). Collaborative writing emphasizes the significance of interactions and cooperation to solve problems in creating a text. Both cognitive and sociocultural theories of L2 learning encourage the use of collaborative writing tasks. From the cognitive perspective, Long's (1996) interaction hypothesis claims that language negotiation for meaning and form facilitates L2 learning. On the other hand, the sociocultural perspective is based on the Vygotskian notion that learning is a socially mediated process (Vygotsky, 1978). Specifically, students engage in scaffolding where lesser-advanced students learn from more advanced learners through their interactions, generating ideas, and languaging (Vygotsky, 1978).

\section{Statement of the problem}

Summary writing is considered a useful albeit sophisticated skill to master. Norisma, Sapiyan, \& Rukaini (2007) stated that summarizing is a significant skill which involves multiple cognitive activities that occur during understanding a text and generating a shortened version of it is known as summarizing. Writing a summary requires students to read a text, find the main points, delete the redundant details, combine similar ideas, and write a text using their own words (Casazza, 1993). Norisma et al. (2007) found that most students failed to summarize texts effectively and concluded that they were weak at summarization. In addition, a study conducted by Chen and $\mathrm{Su}(2011)$ reveals that in writing summaries, students tend to copy rather than paraphrase which can be considered plagiarism.

Due to the difficulties involved in writing a summary, the problem addressed in this study is to determine student's perceptions about collaborative summary writing as a learning approach. Seen in this light, collaborative writing, which has a beneficial effect on writing skills and encourages students to actively take part and produce a text, provides an alternative for teachers to foster their students' summary writing skills due to its collaborative focus. However, to date, few studies have been conducted on collaborative summary writing. Subsequently, this investigation aims to explore and summarize student's perceptions about collaborative summary writing. This study concerns those interested in the educational process, especially in the field of writing, because it sheds light on the collaborative summary writing approach. It is hoped this approach may overcome the shortcomings of traditional summary-writing practices.

The main purpose of this study is to answer the following question:

1. What are Saudi female students' perceptions of collaborative summary writing?

2. What are the problems that may occur during the collaborative writing process?

\section{LITERATURE REVIEW}

Learning a second language 
Language plays an essential role in our lives because it enables us to express our desires, feelings, and ideas. Creating a learning environment where language learning is an efficient experience has been the focus of several previous studies (Sajedi, 2014). Second language acquisition (SLA) involves learning another language besides one's mother tongue either in a classroom setting or outside the classroom (Ellis, 1997). Second language learners are recommended to seek a great exposure to the language being learned (Krashen, 1981). Similar to the first language development, exposure to the second language enables learners to develop different aspects of their new language. Learning a second language is difficult and requires a lot of practice to avoid interference with learners' first language. In addition, a lot of mental and cognitive processes occur in the learner's mind like perception, memorizing, thinking, and so forth, during the acquisition of a second language (Ellis, 2008).

\section{Second language writing}

Language consists of receptive skills (reading and listening) and productive skills (speaking and writing). However, the productive skills, particularly writing, are considered more difficult for second language learners (Gökçe, 2011). Many learners find writing boring and tough because it requires many skills such as good organization, creativity, imagination, and good language knowledge (Gökçe, 2011). Indeed, some students have valuable ideas, but they find composing meaningful thoughts very hard, especially in a second language. Also, some students have negative attitudes toward writing in their second language. Using different pedagogical techniques and strategies in teaching writing may foster students' abilities and raise their level of interest. Powell (1984) conducted a study comparing student's attitudes with their success in writing and found that learners do not like or enjoy writing either in a first or second language because writing tends to be accomplished in only one way most of the time: traditional essay writing. Powell (1984) also stated that writing teachers generally use rigidly structured approaches, and generally do not attempt to change their approach to teaching writing. For instance, teachers mostly ask their students to write in different styles (e.g., narrative or argumentative), but they always teach them using the same methods, without changing their style of teaching. In another study, Fareed, Ashraf, and Bilal (2016) investigated the problems that occur in ESL learner's writing. The study revealed that the major problems with ESL learners' writing are related to a lack of linguistic proficiency, writing anxiety, lack of ideas, reliance on their L1, and weak structural organization. Fareed et al (2016) added that many factors affect learners' problems in writing; for example, untrained teachers, ineffective teaching methods and examination system, a lack of reading and writing practice, large classrooms, low levels of motivation, and lack of ideas. The study also suggested a number of remedies to encourage learners to read and write more extensively such as training teachers and making changes to the examination system.

\section{L2 collaborative learning}

Unlike traditional, individual-focused learning methods, collaborative learning offers great benefits to language learning. However, collaborative learning is defined differently by different scholars; Slavin (1980) defines collaborative learning as when a group of students work together and are given rewards and recognition based on the whole group's performance. On the other hand, Artz and Newman (1990) describe collaborative learning as when a group of learners work as a team to solve a problem, complete a task or achieve a common goal. Indeed, over the last few years, group work has become very common in L2 classrooms. Several studies have emphasized the significance of collaborative work for teaching and learning a second language (see, for example, Shehadeh, 2011; Dobao, 2012; Lin \& Maarof, 2013; Wigglesworth \& Storch, 2012).

The use of pair or group work in the classroom is mainly based on the sociocultural theory, which states that human development is related to social interaction (Vygotsky, 1978). In first language acquisition, children's linguistic and cognitive development (novices) arises from their social interactions with more knowledgeable others (experts). Vygotsky (1978) claimed that the assistance provided to children (in the form of scaffolding) enables children to improve their cognitive and linguistic abilities and therefore allows them to reach their potential level of development. Research has also shown that scaffolding can be applied to second language contexts (Shehadeh, 2011). A number of studies have investigated and analyzed group talk (metatalk or language-related episodes) and concluded a positive effect for second language learning (Shehadeh, 2011). In a comparative study, Pica and Doughty (1985) examined the difference between the effects of teacher-centered classes and cooperative classes; they found that more opportunities for language practice that were given to learners while in small groups produces more scaffolding which enables learners to stretch both their cognitive and linguistic development beyond their current level towards their potential level of development. Based on previous studies, learners should be encouraged to engage in group work to enhance and facilitate their learning (Shehadeh, 2011).

\section{L2 collaborative writing}

For students, writing skills are crucial to master because their writing skills are constantly evaluated as a measure of their academic success (Ismail \& Maasum, 2009). L2 teachers adopt different methods of teaching writing. One of the recommended methods is the incorporation of collaborative writing in which students have a shared responsibility and work together to produce a written text (Storch, 2005). The last few years have witnessed several studies on collaborative writing. Many of these studies have been conducted to examine the benefits of collaborative work on L2 writing (Shehadeh, 2011). The process of collaborative writing allows participants to explore, discuss, cooperate and improve their learning capabilities (Dobao, 2012). Vygotsky (1978) argued that social interaction precedes development. Collaborative writing is built on the Vygotskian notion of having to interact with others, cooperate, and exchange ideas 
in order to allow development to take place (Heidar, 2016). Many studies have attempted to measure the effect of collaborative writing on overall writing performance. Shehadeh (2011) investigated two groups of student's perceptions of collaborative writing; the majority of students in the experimental group reported that the experience was interesting because the other members enabled them to write to higher standards and develop their content, organization and vocabulary skills. Other studies found reinforcement in students' writing in terms of increased grammatical accuracy (Altai, 2015; Storch, 2005; Wigglesworth \& Storch, 2009). In general, the students perceived collaborative writing positively. Positive reactions included opportunities to compare ideas (Storch, 2005) and negotiating meaning (Altai, 2015). Also, Scotland (2014) investigated student's perceptions of assessed group work and found that they had positive perceptions towards it. In another study (Dobao \& Blum, 2013), students were given one collaborative writing task and their reactions were generally positive although a third of them did not see a positive effect on developing grammatical accuracy or vocabulary knowledge. Therefore, more research needs to be conducted about student's perceptions toward collaborative writing in order to gain a better understanding of learners' observed behaviour and language learning outcomes.

\section{Collaborative summary writing}

Summary writing is a significant academic skill for L2 learners and is used most frequently in universities. It requires students to read and understand a passage, then paraphrase and write a summary. Summary writing is considered an essential exercise to enhance students' comprehension skills (Choy \& Lee, 2012). Most students, especially those with limited vocabularies, find summary writing a challenging task. Students encounter several problems when writing a summary; one of these is their inability to paraphrase passages. In addition, many students find summary writing a cognitively demanding task which requires instruction and practice to do it properly, otherwise, students may simply copy rather than accurately paraphrase (Nambiar, 2007). In addition, Perin, Keselman \& Monopoli (2003) conducted a study on summary writing which found that students faced difficulties in finding the main ideas in a text. Furthermore, they found that students who had prior knowledge about the topic were able to summarize the passage more effectively than those who did not. Therefore, collaborative summary writing is introduced as an approach to be used in second language classes in order to improve student's reading and writing skills. Lin and Maarof (2013) investigated both student's perceptions of collaborative writing in summary writing as well as the problems they encountered and found that students had positive perceptions in terms of motivation, grammar, vocabulary and co-construction of knowledge. In the same study, students reported several problems such as limited second language proficiency, unwillingness to offer their opinions, and an inability to finish the task in the allocated time. Shehadeh (2011) found that when students collaborate to compose a summary, it not only reduces the cognitive burden of this complex task, but it also develops different aspects of their writing. Sajedi (2014) has shown that collaborative writing is useful for L2 improvement because it encourages students to become more engaged in the task, enhancing their confidence, and increasing their responsibility.

\section{METHODOLOGY}

The participants of this research study are five Saudi female students currently studying at level two and are majoring in English. Students are chosen in this level particularly because they have mastered paragraph writing but struggle with summarizing, which is a skill included in their course. The students are enrolled in a writing class for three hours a week and had several collaborative writing tasks. The study employed interviews as the method of data collection. A collaborative summary writing activity was given to the students followed by a semi-structured interview with the five participants.

\section{Instrument}

The instrument used was an interview protocol comprised of semi-structured questions to elicit students' perceptions of the experience of collaboration after completing one summary writing task in the classroom (see appendix 1 for the interview questions). Questions are made based on the results of previous studies (see, for example, Shahedah, 2011; Sajedi, 2014). Although the students were used using different collaborative writing experiences in writing essays or paragraphs, this was their first time using a collaborative approach to write a summary.

\section{Procedures}

The study was carried out in the $12^{\text {th }}$ week of a 15 -week semester. Five students were selected randomly as a group. They were given a passage of an appropriate level and length, asked to read it carefully, find the main ideas, delete the irrelevant points and write the summary collaboratively using their own words. Students worked together in which each one of them contributed in one or two sentences to the summary while the other group members checked for grammatical accuracy, use of vocabulary, and clarity of ideas. Then, the participants were interviewed by the researcher. The interviews were informal, semi-structured and were conducted using the student's first language to provide the participants with the opportunity to express their ideas clearly. Furthermore, the researcher interviewed each one of the participants individually to ensure privacy.

\section{FINDINGS}

Students' perceptions of collaborative summary writing 
Based on the participant's answers during the interviews, all of them agreed that collaborative summary writing is beneficial in different ways especially in terms of improving their grammar, expanding their vocabulary, and improving their paraphrasing skills. Participant A, for example, pointed out that:

"I prefer collaborative writing, particularly when everyone of the group provides her sentence structure and we as group members decide for the best."

So, participant A relates collaborative writing to the ability to build the best sentence structure. Another feature of collaborative writing is that students might benefit from the feedback given by the other group members in order to improve their writing. In this regard, participant B said that:

"I think group interactions are useful because they help to correct errors and remind us of things we might forget when working individually."

Participant $\mathrm{C}$ also found group interactions important in improving her writing skills and claimed:

"...by interacting, we search, discuss and think of the best words and grammatical structures that fit in the context."

Participant $\mathrm{C}$, therefore, claimed that group interactions are effective to improve both vocabulary and grammar. Further, participant D said that:

"My level of English is not proficient, so I need someone else to polish my language and group discussions are often valuable."

Overall, the respondents relate collaborative writing to the development of L2 writing in different areas (e.g., language proficiency, grammar improvement, expanding of vocabulary and developing paraphrasing skills).

The four participants revealed that writing collaboratively was able to positively affect their confidence and motivation for writing. For example, participant E reported that:

"If I make a suggestion and they accept it, my confidence increases."

In contrast, participant $\mathrm{C}$ claimed that writing collaboratively did not affect either her confidence or motivation, revealing that collaborative writing might even destroy someone's self-confidence, reporting that:

"If a student is put with a group that has members who are beyond her level, this might make her less confident."

In sum, the majority of the participants $(80 \%)$ claimed that collaborative writing has a positive effect on their motivation and confidence.

Students were also interviewed about the evaluation criteria. Two participants thought receiving a group grade is fair, whereas two other participants reported that it depends on the members of the group, the fifth one thought it is unfair to have a group grade. For example, participant D claimed:

"If the group members are cooperative, then I think the marking is fair."

Therefore, participant $\mathrm{D}$ relates the fairness of evaluation to the collaboration of the group members. On the other hand, participant $\mathrm{C}$ had a different point of view:

"...in all kinds of collaborative learning, I think it is unjust that all members take the same grade while there is a disparity in their contributions."

Therefore, participant $\mathrm{C}$ sees it from a different angle, that grading should be related to each member's own contribution. Overall, the participants had different views about accepting group evaluation.

Most of the participants claimed that the success of collaborative writing depends largely on the group members in the team. Participant B, for example, claimed that:

"Collaborative writing, in general, is a very useful tool especially if you have group members who are similar to your level or beyond."

Therefore, participant B finds the usefulness of collaborative writing relies on the members of the group. Participant $\mathrm{C}$ also agrees:

"I believe the success of collaborative writing depends largely on who are you going to join? Is the relationship between the group members strong? Is the work divided in a way that is fair for all the members?"

So, participant $\mathrm{C}$ thinks writing collaboratively depends on the group members, their relationships, and how the work is divided among them (i.e., whether fairly or not). Similarly, participant A said:

"I prefer it when the professor gives us the opportunity to decide who to be within the group, instead of dividing us randomly."

Overall, the participants claimed that group members play a crucial role in the success of collaborative summary writing.

\section{Students' problems of collaborative summary writing}

When the participants were asked about the problems they encountered in the process of collaboration, the majority of them reported that the main problem with collaborative writing was working with uncooperative group members. Participant E, for example, mentioned that:

"Sometimes, the group members rely mostly on one or two members, while the rest are doing nothing."

For participant E, some group members are more responsible than others. Participant B agreed with participant E and claimed:

"The members' different levels will make the most work on those who are more proficient." 
So, participant B views the problem differently and thinks that some members do not collaborate because their level of proficiency is not sufficient enough. Participant $\mathrm{C}$ also sees the issue from a different angle, and claimed:

"Sometimes, all the group members will be thanked by the doctor for the great work while in reality, only one or two members have participated. This might affect the relationship among group members."

For participant $\mathrm{C}$, some group members may not contribute at all to the group discussions but will be praised by their tutor for great work, which may lead to negative attitudes toward such members. Overall, all the participants found the lack of collaboration as the major problem in writing as a group.

Another problem that was reported by only two participants is the limited time that is given for writing. For instance, participant B claimed that:

"Sometimes, collaborative writing is a kind of wasting time as some members are dependent on the others."

For participant B, some members wait for the others to do the task and do not provide any contribution. For participant $\mathrm{B}$, working alone might be better than wasting time while asking for other members' contributions and opinions.

Overall, the participants perceived collaborative summary writing positively and they wish to do it again. They find it positively affects their grammar, vocabulary, paraphrasing skills and motivation. However, they encountered some problems during the process of collaboration such as working with uncooperative group members and limited time.

\section{DISCUSSION}

From the interview responses, all the participants revealed positive perceptions of collaborative writing in terms of several different aspects. In terms of language development, the participants claimed that collaborative writing was helpful in enriching their writing skills, which is in harmony with previous studies. For example, Shehadeh (2011) stated that the collaborative experience had a positive impact on students' L2 writing development. In terms of grammar development, the findings of the current study echo several prior studies' findings. For instance, Lin and Maarof (2013) and Storch (2005) found that collaboration affected the participants' grammatical accuracy positively. In terms of vocabulary development, Gökçe (2011) and Shehadeh (2011) indicated an improvement in vocabulary and quality of writing after writing collaboratively. Therefore, students prefer writing collaboratively because a member can be proficient in some aspects like grammar, but not others like vocabulary. As a result, group members complement each other and collaborate to produce a better summary.

Another feature that was mentioned by the participants is sharing ideas and learning from each other, which is frequently cited in past studies (Shehadeh, 2011; Storch, 2005; Wigglesworth \& Storch, 2012). By writing together, students exchange ideas, make suggestions, paraphrase sentences, and negotiate meaning. These interactions enrich their vocabulary, foster their grammatical accuracy, and enhance their overall language proficiency. When someone makes a mistake, others will provide corrective feedback and in this way, the final product will be improved. Such interactions open students' eyes to aspects of language they may not have considered before. Discussing these issues with each other helps them think and search deeply until they reach a solution to a problem they encounter. Therefore, their overall language will be developed and they will gain benefits in different aspects of L2 writing.

Most of the participants indicated that collaborative writing supported their motivation and confidence in writing. This finding confirms past studies (Shehadeh, 2011; Gökçe, 2011; Yong, 2006) whose participants claimed that collaborative writing fostered their self-confidence. In addition, Lin and Maarof (2013) conducted a study on Malaysian students, which revealed that collaborative summary writing increased students' motivation toward writing. When a member receives positive feedback for her contribution or when the other members accept their suggestions, this increases confidence and motivation toward writing. Therefore, the students will be more engaged and eager to write. However, contrary to the majority of studies, participant $\mathrm{C}$ claimed that collaborative writing might affect their motivation negatively. For them, being a part of a group which has more competent or dominant students might make them not accept their contributions and suggestions. As a result, this may lead them becoming less confident and unmotivated to participate. Therefore, teachers should be mindful of this in the class and always remind their students of best practice for polite social interaction. Although having students with different levels in the same group has positive effects, it also can lead to negative ones.

Scotland's (2014) study that was conducted with Qatari students showed they claimed to accept a group grade which contradicts the findings of the current study. Four of the participants in this study pointed out that a group evaluation would be accepted only if all the group members are cooperative and one participant did not accept it at all, although they did not really receive a mark for their collaborative summary writing. The reason for this might be that some members work harder than others, and so deserve better marks. Normally, in group writing, a member's mark is tied to the performance of the whole group. Plastow, Spiliotopoulou, and Prior (2010) made a comparison between individual marks and group marks for 230 students. Surprisingly, the results indicated that no statistical correlation was found between individual and group marks. This is an indicator that group evaluation is not valid compared to individual evaluation. Maybe that is why the participants in the present study do not find group evaluation reflects the real ability of each member. For example, higher-ability members might positively affect the mark of lower-ability members and vice versa. 
All the participants agreed that the kind of members in a group has a great influence on collaborative writing. This is because collaborative writing encourages students to take responsibility not only for their own writing but also share the responsibility to help other members of the group in their accomplishing goals. This is in line with Talib \& Cheung's 2017) findings, who claimed that the success of collaborative writing is largely related to teamwork. A number of participants prefer to choose group members by themselves. So, maybe having members who are close to each other will lead to better interaction and therefore better writing. Some students may find it difficult to work with people they are unfamiliar with. Also, some students may prefer to choose team members in order to make sure they will be beneficial to the whole group. Some members are passive and unwilling to participate which reduces the enjoyment and cooperation of the whole group. In this way, the other members will not benefit and might become demotivated to participate which will be reflected by the overall quality of their writing. The participants also agreed that not everybody provided an equal amount of effort which corresponds with past studies (Lin \& Maarof, 2013; Sajedi, 2014). In addition, Altai (2015) pointed out that some of the participants in her study complained about uncooperative group members. The reason for this might be that the group members change from one task to another. In some cases, the group members contribute equally, while they do not in others. Further, some members might be irresponsible and unwilling to provide their ideas and participate just because they expect other members to do so. In other words, some members (passengers) depend on others, particularly those who are more proficient in L2 writing skills. Passengers or free riders are those who do not provide any contributions to the group but still receive benefits (Scotland, 2014). The problem of passengers in group writing is very difficult to solve. Teachers need to always encourage their students to participate and make contributions as this will be reflected in their level of development.

Another difficulty that two participants encountered was the limited time to write collaboratively. This finding is consistent with some previous studies that found working in groups take longer time than working individually (Storch, 2005; Lin \& Maarof, 2013), but contradicts Altai's (2015) findings where the participants declared that collaborative writing decreased the amount of time they spent on writing texts. Dobao (2012) argued that when assigning the same amount of time, students who write individually produce longer texts than those who write in pairs or as part of a group. As for the current study, the participants may not be proficient enough in English as they are in level two. This means that writing collaboratively will require more of their time to suggest, explore, discuss, pool ideas, talk about the best ways to use language and finally decide on the best choices. Therefore, the time required is not only for writing itself but also for what happens before the writing process as part of the collaboration.

\section{CONCLUSION}

Research and empirical studies on collaborative writing have suggested its significance for teaching a second language. This study was conducted to investigate student's perceptions toward collaborative summary writing. The general principle behind collaborative writing is that students work together as a team to achieve a common goal, namely that each student learns from the others. Hence, considering the perceptions of students toward collaborative writing and problems that occur in the process of writing, it can be concluded that students have a generally positive attitude toward collaborative summary writing, although they encountered some problems in the process of collaboration. The findings of this study echo a vast number of past studies and suggest a lot of advantages for using collaborative writing in enhancing different aspects of language proficiency and paraphrasing skills as well as building motivation toward L2 writing. Further, some problems occurred: a lack of group collaboration and limited time. Therefore, L2 teachers should encourage their students to reflect on their perceptions of collaborative writing because this provides them with a great opportunity to discuss and learn from these discussions.

\section{Limitations and further studies}

This study has a number of limitations that should be mentioned. First, the present study is limited in that it is based solely on five participants' reports gathered by semi-structured interviews. Thus, a general claim cannot be made about students' perceptions of collaborative summary writing as the researcher worked with only a limited number of participants. However, the participant's responses did reflect a number of issues highlighted in previous research. Second, all the participants in this study are studying at the same level; level two. Having more participants from different levels could affect the results. In addition, the limited meant that the participants only collaborated on one summary writing task. If there was more time, the participants could do more collaborative summary writing tasks and so the findings would be more reliable. Consequently, further studies need to be conducted in order to eliminate or mitigate these limitations.

\section{APPENDIX}

Interview questions

1/You have been in a collaborative summary writing experience, how do you feel about this experience in general?

2/ Was collaborative writing helpful? Why? Or why not?

3/ Tell me what is it like to interact with members of your group in order to compose a piece of writing?

4/ What do you think of the feedback you get from your group members?

5/ Does collaborative writing help you to understand more about paraphrasing? How? 
6/ What are the effects of collaborative writing on personality factors like motivation and confidence? 7/ Based on your own experience, tell me the advantages and disadvantages of collaborative writing? 8/ What are the problems you face in collaborative summary writing?

9/ Is it fair that all group members take the same grade?

\section{REFERENCES}

[1] Altai, Y. (2015). The effect of collaboration on Omani students' writing: A comparison between individual, pair and group work. European Scientific Journal, 1, 154-171. Retrieved Sep, 2019 from https://eujournal.org/index.php/esj/article/view/5554/5349.

[2] Artz, A. F., \& Newman, C. M. (1990). Cooperative learning. Mathematics Teacher, 83, 448-449.

[3] Casazza, M. (1993). Using a Model of Direct Instruction to Teach Summary Writing in a College Reading Class. Journal of Reading, 37(3), 202-208.

[4] Chen, Y., \& Su, S. (2011). A genre-based approach to teaching EFL summary writing. ELT Journal, 66(2), 184-192. doi:10.1093/elt/ccr061

[5] Choy, S. C., \& Lee, M. Y. (2012). Effects of teaching paraphrasing skills to students learning summary writing in ESL. Journal of Teaching and Learning, 8(2), 77-89. doi:10.22329/jtl.v8i2.3145.

[6] Dobao, A. F. (2012). Collaborative writing tasks in the L2 classroom: Comparing group, pair, and individual work. Journal of Second Language Writing, 21(1), 40-58.

[7] Dobao, A. F., \& Blum, A. (2013). Collaborative writing in pairs and small groups: Learners' attitudes and perceptions. System, 41(2), 365-378. doi:10.1016/j.system.2013.02.002.

[8] Ellis, R. (2008). Understanding second language acquisition 2nd Edition - Oxford Applied Linguistics. New York, NY: Oxford University Press.

[9] Ellis, R. (1997). Second Language Acquisition. New York, NY: Oxford University Press.

[10] Fareed, M., Ashraf, A., \& Bilal, M. (2016). ESL learners' writing skills: Problems, factors and suggestions. Journal of Education \& Social Sciences, 4(2), 83-94. doi:10.20547/jess0421604201.

[11] Gökçe, İ. (2011). Effects of collaborative writing on attitudes of learners toward writing at Anadolu University Preparatory School (Master's thesis, Bilkent University, Ankara, Turkey). Retrieved Sep, 2019 from http://www.thesis.bilkent.edu.tr/0001839.pdf.

[12] Heidar, D. M. (2016). ZPD-assisted Intervention via Web 2.0 and Listening Comprehension Ability. English for Specific Purposes World, 17(4), 1-17.

[13] Ismail, S., \& Maasum, N. R. (2009). The effects of cooperative learning in enhancing writing. SOLLS.INTEC 09 International Conference. Putrajaya, University Kebangsaan Malaysia

[14] Krashen, S. D. (1981). Second language acquisition and second language learning. New York, NY: Oxford University Press.

[15] Lin, O. P., \& Maarof, N. (2013). Collaborative writing in summary writing: Student perceptions and problems. Procedia Social and Behavioral Sciences, 90, 599-606.

[16] Long, M. H. (1996). The role of the linguistic environment in second language acquisition. In W. C. Ritchie, \& T. K. Bhatia (Eds.), Handbook of language acquisition Second language acquisition. New York: Academic Press. doi.org/10.1016/B9780125890427/50015-3

[17] Nambiar, R. M. K. (2007) Enhancing academic literacy among tertiary learners: A Malaysian experience. $3 L$ The Southeast Asian Journal of English Language Studies, 13, 77-94

[18] Norisma I., Sapiyan B., \& Rukaini A. (2007). An analysis on student-written summaries: a step towards developing an automated summarization assessment. Proceedings of the International Conference on Electrical Engineering and Informatics Institut Teknologi Bandung, Indonesia.

[19] Perin, D., Keselman, A., \& Monopoli, M. (2003). The academic writing of community college remedial students: Text and learner variables. Higher Education, 45(1), 19-42.

[20] Pica, T., \& Doughty, C. (1985). The role of group work in classroom second language acquisition. Studies in Second Language Acquisition, 7(02), 233. doi:10.1017/s0272263100005398.

[21] Plastow, N., Spiliotopoulou, G., \& Prior, S. (2010). Group assessment at first year and final degree level: A comparative evaluation. Innovations in Education and Teaching International, 47(4), 393-403. doi:10.1080/14703297.2010.518427.

[22] Powell, B. J. (1984). A comparison of students' attitudes and success in writing. Journal of Negro Education, 53, 114-123.

[23] Sajedi, S. P. (2014). Collaborative summary writing and EFL students' L2 development. Procedia - Social and Behavioral Sciences, 98, 1650-1657. doi:10.1016/j.sbspro.2014.03.589.

[24] Scotland, J. (2014). How the experience of assessed collaborative writing impacts on undergraduate students' perceptions of assessed group work. Assessment \& Evaluation in Higher Education, 41(1), 15-34. doi:10.1080/02602938.2014.977221.

[25] Shehadeh, A. (2011). Effects and student perceptions of collaborative writing in L2. Journal of Second Language Writing, 20(4), 286-305. doi:10.1016/j.jslw.2011.05.010.

[26] Slavin, R. E. (1980). Cooperative learning. Review of Educational Research, 50(2), 315. doi:10.2307/1170149.

[27] Storch, N. (2005). Collaborative writing: Product, process, and students' reflections. Journal of Second Language Writing, 14(3), 153-173. doi:10.1016/j.jslw.2005.05.002.

[28] Storch, N. (2011). Collaborative Writing in L2 Contexts: Processes, Outcomes and Future Directions'. Annual Review of Applied Linguistics, 31, 275-288. doi.org/10.1017/S0267190511000079.

[29] Talib, T., \& Cheung, Y. L. (2017). Collaborative writing in classroom instruction: A synthesis of recent research. The English Teacher, 46(2), 43-57.

[30] Vygotsky, L. (1978). Mind in society: The development of higher psychological processes. Cambridge, MA: Harvard University Press. doi:10.1016/j.sbspro.2013.07.131. 
[31] Wigglesworth, G., \& Storch, N. (2009). Pair versus individual writing: Effects on fluency, complexity and accuracy. Language Testing, 26(3), 445-466. doi:10.1177/0265532209104670.

[32] Wigglesworth, G., \& Storch, N. (2012). What role for collaboration in writing and writing feedback. Journal of Second Language Writing, 21(4), 364-374. doi.org/10.1016/j.jslw.2012.09.005.

Noura Alawaji is from Saudi Arabia. She was born on 6-2-1991. She obtained a BA degree with an honor from Qassim University in English Language in 2012. She is currently an MA student at applied linguistics in Qassim University. She is an English trainer at College of Technology in Arrass. 